\title{
Glass-bottled drinking water: a time capsule to study the historic presence of hazardous chemicals using effect-based methods
}

Johan Lundqvist ${ }^{1,2^{*}}$, Kenneth M. Persson ${ }^{3,4,5}$ and Agneta Oskarsson ${ }^{1,2}$

\begin{abstract}
Background: Contamination of drinking water by hazardous chemicals can be associated with human health risks. Recent studies using effect-based in vitro methods have demonstrated that a large part of the observed toxic effects are caused by unknown chemicals. In this study, we have used a panel of effect-based methods to study the presence of chemical contaminants in a unique material; glass-bottled Swedish tap water collected during the 1990s. These water samples were compared to drinking water from the same source waters and drinking water facilities, yet collected about 25 years later, in 2020.

Results: Samples were concentrated by solid phase extraction and evaluated for the following activities; estrogen receptor activity, androgen receptor activity, antiandrogenic activity, aryl hydrocarbon receptor activity, and oxidative stress response. We observed aryl hydrocarbon receptor activities in almost all studied samples and estrogen receptor activity in three out of ten studied samples. No activities were observed for androgen receptor activity, antiandrogenic activity or oxidative stress response. In general, observed activities were more frequent and higher in the water samples collected during the 1990s as compared to the corresponding samples collected in 2020.

Conclusions: This study demonstrates that it is possible to conduct an effect-based evaluation of the presence of hazardous chemicals in drinking water, with as small starting volume as $330 \mathrm{~mL}$, by using miniaturized bioassays. Further, by comparing the glass-bottled water samples with newly collected water samples from the same drinking water treatment facilities, our results indicate that the presence of aryl hydrocarbon receptor and estrogen receptor activating compounds in the drinking water has decreased over the approximately quarter of a century that is separating the two sampling occasions. This difference could be due to improved raw water quality and/or improved treatment efficiency in the treatment plants.
\end{abstract}

Keywords: Effect-based methods, Drinking water, Estrogen receptor activity, Aryl hydrocarbon receptor activity, Bottled water

\section{Background}

Drinking water is our most important food item, with an average daily consumption of 2-2.5 L [1]. Drinking

\footnotetext{
*Correspondence: Johan.Lundqvist@slu.se

1 Department of Biomedical Sciences and Veterinary Public Health,

Swedish University of Agricultural Sciences, P.O. Box 7028, 75007 Uppsala, Sweden

Full list of author information is available at the end of the article
}

water is consumed by everyone in the population, from infants to the elderly, including vulnerable groups such as persons with chronic illnesses. The high consumption of drinking water and the fact that, in most cases, the consumed drinking water is from one single drinking water treatment plant for extended periods of the life span (years to decades) imply that also very low levels of hazardous chemical pollutants in drinking water could potentially constitute a risk to human health and should be monitored regularly. 
Current drinking water regulation regarding chemical contaminants is in most countries, including the European Union, based on defined maximum concentration levels of a very limited number of chemicals or groups of chemicals [2]. There is, however, a substantial body of scientific literature showing that these well-known environmental pollutants can only explain a relatively small proportion of the observed toxicity in water samples, especially for toxicity endpoints such as reactive toxicity, xenobiotic metabolism and oxidative stress [3-7]. For some of these endpoints, the well-known environmental pollutants can only explain as little as $0.1-5 \%$ of the observed toxicity, implying that up to $99.9 \%$ of the toxicity is caused by unknown chemicals or mixture effects $[3,4]$. It has therefore been suggest that effect-based methods should be incorporated in the drinking water quality control $[7,8]$, as they can integrate the effects of both known and unknown chemicals as well as potential mixture effects that can occur when an organism is simultaneously exposed to multiple chemicals. Thereby, the effect-based methods can help to bridge the current knowledge gap and contribute to the societal goal of universal access to safe drinking water. Oskarsson et al. [9] recently reported the that the drinking water was contaminated by oxidative stress inducing and antiandrogenic compounds during the drinking water treatment process in a Swedish drinking water treatment plant, while all the chemical parameters were acceptable according to the current legislation. This highlights the need for effect-based methods in drinking water quality control.

In Sweden, tap water has been the major source of drinking water for a long time and remains so today. During the 1980s and 1990s, the brewery industry started to promote bottled drinking water and spring water on the Swedish market, sometimes with implied arguments that the bottled water would be of higher quality than tap water. In a reaction to this, some of the publically owned drinking water producers started to bottle the tap water that they produced in glass bottles and used the bottles for marketing purposes, e.g., in conjunction to a jubilee of the company or the city where the plant was located. A selection of these bottles of tap water was collected at Lund University, Sweden.

In this study, we have used a panel of cell-based bioassays to evaluate the effects of hazardous chemicals in five of these approximately 25 -year-old water samples (Fig. 1). In addition, we collected new drinking water samples from the same five drinking water treatment plants. By comparing these unique samples, we were able to compare the bioactivities, indicating presence of hazardous chemicals, in drinking water 25 years ago with the current situation.

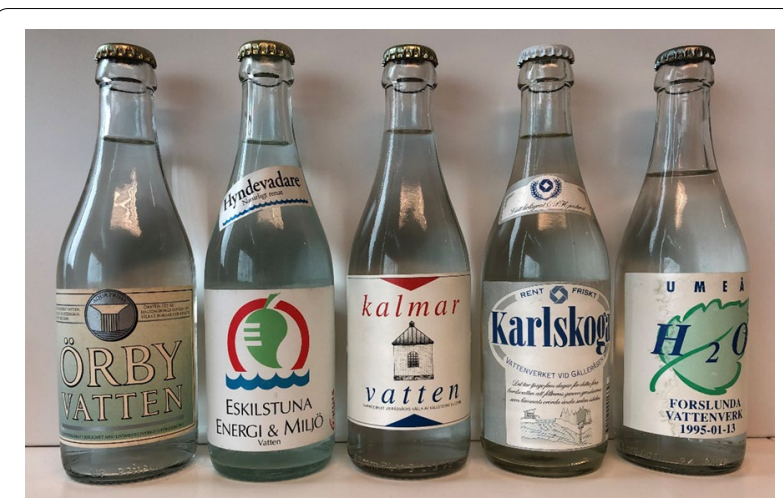

Fig. 1 Bottled drinking water samples collected during the 1990s, stored at Lund University for approximately 25 years and then used for this study. Photo: the authors

\section{Methods}

\section{Water samples}

Bottled tap water from the publically owned drinking water producers in the Swedish municipalities Helsingborg, Kalmar, Eskilstuna, Karlskoga, and Umeå were collected during the 1990s and stored for approximately 25 years at Lund University, Sweden. Four of the drinking water plants used artificial recharge of surface water (lake water for Helsingborg and river water for Umeå, Karlskoga, and Eskilstuna) and one used ground water (Kalmar). The drinking water treatment plants in Helsingborg and Umeå have been complemented with UV treatment in the time between the sampling occasions. For the other plants, the treatment technologies have been unchanged. At the time of bottling, the water was collected in a tanker truck, transported to a bottling plant, carbonated and then bottled in 330-mL glass bottles. These bottles were stored in room temperature and protected from direct sunlight. During the fall of year 2020, new drinking water samples were collected from the same drinking water producers. These water samples were collected in plastic bottles intended for water sampling (VWR, sterile water sampling bottles, catalog no. VWRI331-0269). To ensure that these bottles did not leak compounds to the samples that could cause activity in our assays, Milli-Q water was stored in a bottle overnight and then extracted with solid phase extraction. The extract was then tested in all assays at a relative enrichment factor of 50 and found to exert no statistically significant effects in any of the assays used, evaluated by Student's t-test (fold change vs vehicle control was $1.1 \pm 0.06$ for estrogenicity, $1.0 \pm 0.02$ for androgenicity, $1.1 \pm 0.04$ for antiandrogenicity, $1.0 \pm 0.14$ for AhR activity, and $1.1 \pm 0.19$ for Nrf2 activity). Drinking water samples were collected by the drinking water treatment plant operators and immediately sent to our laboratory. After 
arrival, the water samples were stored at $-20^{\circ} \mathrm{C}$ awaiting sample preparation.

The samples were concentrated using solid phase extraction (SPE) with Oasis PRiME HLB 6 cc 200 mg columns (Waters), using an 8-channel automated SPE system (SPE-03 system, Promochrom Technologies). The SPE column was preconditioned with two times $5 \mathrm{~mL}$ 99\% methanol $(5 \mathrm{~mL} / \mathrm{min})$. The sample was then added with a flow rate of $20 \mathrm{~mL} / \mathrm{min}$, followed by air drying of the column by two times $5 \mathrm{~mL}$ of air. The column was then eluted with $10 \mathrm{~mL} 99 \%$ ethanol. The ethanol was evaporated by vacuum and exchanged for a smaller volume of $99 \%$ ethanol. In the SPE process, $330 \mathrm{~mL}$ of each water sample was concentrated to $66 \mu \mathrm{L}$, giving a concentration factor of 5000. The concentrated samples were then diluted in cell culture medium at least 100 times. The concentrations of the water samples in the cell cultures are expressed as the relative enrichment factor (REF), which is calculated by dividing the concentration factor of the SPE with the dilution factor in the cell culture medium. The highest tested REF for all samples was 50. The concentration of ethanol in the vehicle was kept constant at $1 \%$ across all exposure groups.

\section{Effect-based methods}

In this study, we used a panel of effect-based methods targeting early molecular events in health-relevant toxicity pathways. The effect-based methods were selected based on their relevance to human health and covered the following effects; aryl hydrocarbon receptor activation, estrogen receptor activation, androgen receptor activation and inhibition, and oxidative stress response (Nrf2 activation). The methods are summarized in Table 1 and described in detail in the supplementary information.

The stably transfected T47D cells used for estrogen receptor activity was obtained from Signosis (Santa Clara, CA, USA), AR EcoScreen and DR EcoScreen cells were obtained from Hiro Biotech via the Japanese Collection of Research Bioresources (JCRB), National Institutes of Biomedical Innovation, Health and Nutrition (Ibaraki city, Osaka, Japan), and MCF-7/AREc32 was obtained from Ximbio (London, UK). All luciferase bioassay experiments were conducted in white-walled 384-well cell culture plates with transparent bottom (Corning) and cytotoxicity testing was performed in clear plastic 384-well cell culture plates (Corning). All water extracts were analyzed in dilution series and vehicle controls and a dilution series of the reference compound was included on each experimental plate. Cells were seeded in multiwell plates and left to proliferate for $24 \mathrm{~h}$. The cells were then exposed to concentrated water samples for $24 \mathrm{~h}$ prior to cell lysis and luminescence measurement. Luminescence was measured using a Tecan Spark plate reader. To ensure that experiments were carried out under noncytotoxic conditions, all water samples were tested for cytotoxicity using CellTiter $96^{\circledR}$ AQueous One Solution Cell Proliferation Assay (MTS) (Promega) for all cell lines. A cell viability of $<80 \%$ of the vehicle control was defined as cytotoxicity.

\section{Data evaluation and statistical analysis}

All samples were tested for bioactivity in a twofold dilution series with four concentrations. For receptor-based activities, the activity was first normalized to controls and then normalized to percent of maximum activity. For agonistic activities, the maximum activity was defined as the highest activity recorded for the reference compound. For antagonistic activity, the maximum activity was defined as the control samples treated with DHT but not OHF. As there is no clear maximum response for Nrf2 activity, the activity for this endpoint was normalized to the vehicle control. As we only analyzed activities up to $30 \%$ of the maximum response, linear regression was used to characterize the dose-response curves, as proposed by Escher et al. [10].

The results were statistically evaluated using a oneway ANOVA followed by Dunnett's multiple comparisons test, performed in GraphPad Prism. A sample was defined as active if any of the tested REF values were statistically significantly higher (agonistic activities) or lower (antagonistic activity) as compared to the vehicle control $(p<0.05)$. For all samples defined as active, effect

Table 1 Summary of effect-based methods used in this study

\begin{tabular}{lll}
\hline Endpoint & Cell line & Reference compound \\
\hline Estrogen receptor activation & Stably transfected T47D & 17ß-Estradiol (E2) \\
Androgen receptor activation & AR EcoScreen GR-KO M1 & Dihydrotestosterone (DHT) \\
Androgen receptor antagonism & AR EcoScreen GR-KO M1 & Hydroxyflutamide (OHF) in addition to a fixed \\
& & $\begin{array}{l}\text { concentration of 200 pM DHT to stimulate the } \\
\text { receptor }\end{array}$ \\
Aryl hydrocarbon receptor activation & 2,3,7,8-Tetrachlorodibenzodioxin (TCDD) \\
Oxidative stress, Nrf2 activity & DR EcoScreen & Tert-Butylhydroquinone (tBHQ) \\
\hline
\end{tabular}


concentrations were calculated. For agonistic activities, the effect concentration $5 \%\left(\mathrm{EC}_{5}\right)$ was calculated. $\mathrm{EC}_{5}$ is expressed as REF, i.e., the enrichment factor of the water needed to give an effect which is $5 \%$ of the maximum response of the reference compound.

The dose-response curves for E2, DHT, OHF, and TCDD was characterized using a four-parameter sigmoidal curve-fit. For tBHQ, curve was characterized using linear regression. All curve-fitting and data evaluation was performed in GraphPad Prism. $\mathrm{EC}_{5}, \mathrm{IC}_{30}$ and $\mathrm{EC}_{\mathrm{IR} 1.5}$, respectively, were calculated for the reference compounds.

The bioanalytical equivalent concentration (BEQ) for each sample was calculated as described by Escher et al. [11]:

$$
B E Q=\frac{\left(E C_{5}\right)_{\text {referencecompound }}}{\left(E C_{5}\right)_{\text {sample }}} .
$$

\section{Results and discussion}

\section{Estrogen receptor activity}

Initially, the concentrated water samples were tested for cytotoxicity in the stably transfected T47D cell line using MTS test at REF 50. No cytotoxicity was observed for either of the samples (Additional file 1: Figure SI1).

The samples were then tested for their estrogenicity in a twofold four concentration dilution series starting at REF 50. We observed estrogenic activities in three of the ten analyzed samples (Fig. 2). For these three samples, $B E Q$ values were calculated in the form of E2 equivalent

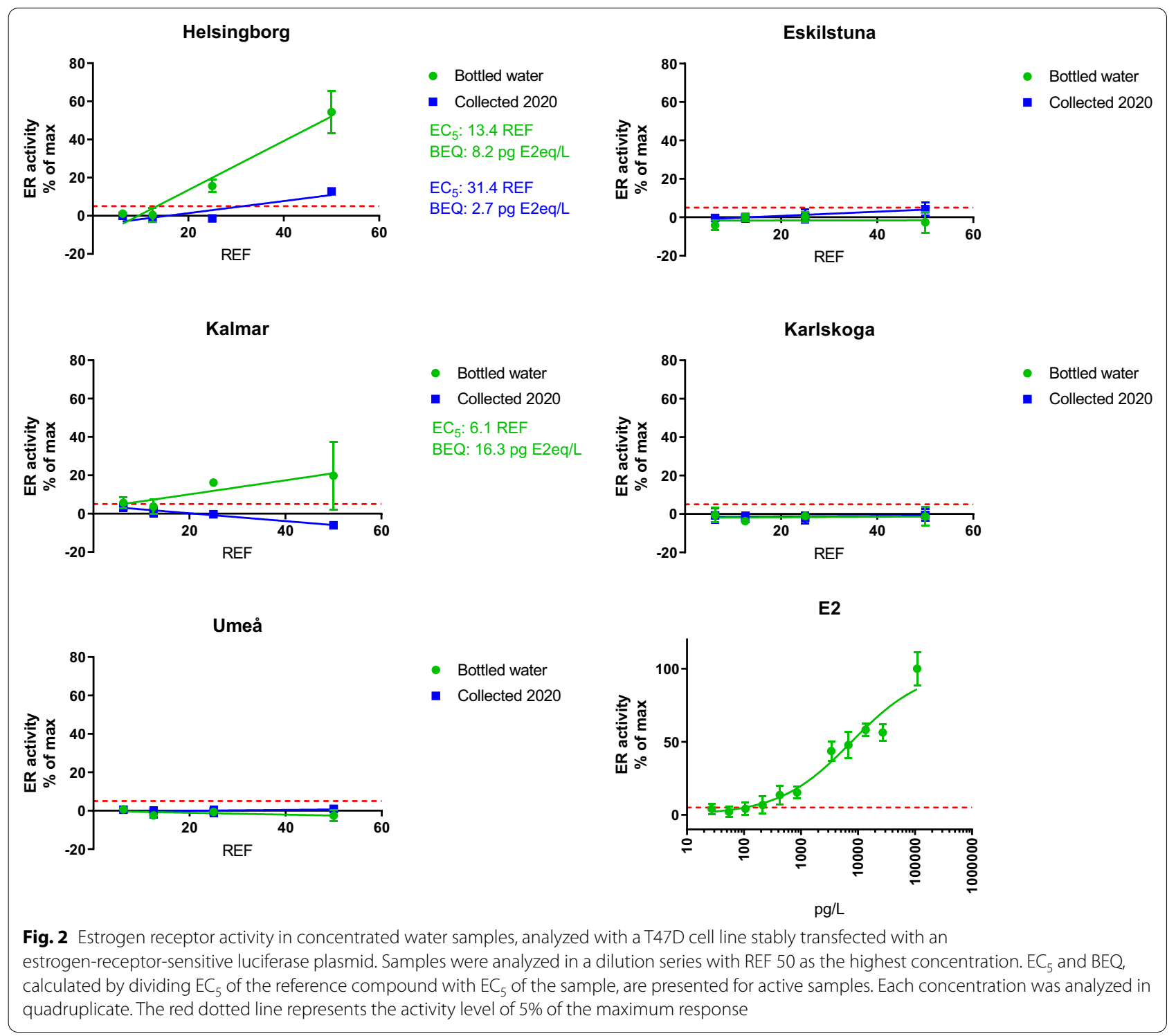


concentrations. $\mathrm{BEQ}$ and $\mathrm{EC}_{5}$ values are presented in Fig. 2. For the reference compound E2, the $\mathrm{EC}_{5}$ was used to calculate a corresponding BEQ value of the samples with a statistically significant effect compared to vehicle controls at least at REF 50. Neither of the inactive samples reached an activity of $5 \%$ of assay maximum (Fig. 2). $\mathrm{EC}_{5}$ of $\mathrm{E} 2$ was corresponding to a $\mathrm{BEQ}$ value of $2.1 \mathrm{pg}$ $\mathrm{E} 2 / \mathrm{L}$ in a concentrated water sample. Hence, the samples not showing an activity of $5 \%$ or more at REF 50 had a $\mathrm{BEQ}$ value $<2.1 \mathrm{pg} / \mathrm{L}$ E2.

Generally, the observed estrogenic activities in the samples were low. In four out of five samples collected in 2020, the BEQ was $<2.1 \mathrm{pg} E 2 \mathrm{eq} / \mathrm{L}$, and in the fifth sample the BEQ was $2.7 \mathrm{pg}$ E2/L. In the bottled drinking water samples, higher estrogenicity was observed, in the range 8-16 pg E2eq/L, which is still a low activity compared to many other published studies. However, for both Helsingborg and Kalmar, a clear difference can be observed between the bottled water and the water sample collected in 2020. For Helsingborg, the BEQ value was decreased by approximately $60 \%$ in the 2020 sample compared to the approximately 25 -year-old water sample. UV disinfection was introduced in the treatment of drinking water in Helsingborg in 2006, which may contribute to the reduction of estrogenic activity in the sample collected in 2020. Degradation of estrogens, and especially estrone, in drinking water by UV photolysis has been reported [12]. For Kalmar, the BEQ was decreased with approximately $90 \%$ in the newly collected sample compared to the bottled water. There was no change in the drinking water treatment and the difference could be due to improved raw water quality.

The observed activities can be compared to the benchmark value of $1 \mathrm{ng} / \mathrm{L}$ of E2 in drinking water for assessing occurrence and treatment efficacy, recommended by WHO [13] during the revision of the EU drinking water directive. However, in the recently adopted directive, E2 is not included with a parametric value, but in the watch list, to be set up by the European Commission [2]. It should, however, be noted that the estrogenic activities observed in these samples are all considerably below this benchmark value of $1 \mathrm{ng}$ E2/L. Previous studies of estrogenic activity in drinking water, using different bioassays based on mammalian cells, have reported BEQ values in the range of 0.01-5 ng E2eq/L [14-20]. Effect-based trigger values for estrogenic activities in drinking water in the range 0.1-3.8 $\mathrm{ng} \mathrm{E} 2 \mathrm{eq} / \mathrm{L}$ have been proposed [11, $15,21,22]$. All samples showing estrogenic activity in this study had an activity that was considerably lower than the proposed effect-based trigger values.

Bottled water in plastic containers, mainly polyethylene terephthalate (PET) bottles, has been suspected to be a potential source of exposure to estrogenic compounds migrated from the plastic. Several studies have used bioassays to investigate estrogenic activities in mineral water stored in PET bottles and detected activities at various frequencies; in none of the samples [23], in 10\% [24], and $60 \%[25]$ of the tested samples. Wagner and Oehlemann [25] reported estrogenic activity, corresponding to 1.9-12.2 pg E2eq/L in the samples with detected activities. They also compared estrogenic activities in water, originating from the same five springs, packed in either PET or glass bottles and found higher activities in water from PET than in glass bottles in three of the five pair of comparisons. However, the estrogenic activities in water from PET bottles have not been clearly related to migration from the plastic. The sources could be laboratory equipment, contamination during the washing steps of the reusable bottles or the water itself [26].

\section{Androgen receptor activity}

Initially, the concentrated water samples were tested for cytotoxicity in the stably transfected AR-EcoScreen cell line using MTS test at REF 50 . No cytotoxicity was observed for either of the samples (Additional file 1: Figure SI2).

The samples were then tested for androgenic activity, but no androgenic activity was observed in any of the samples and neither of the samples reach $5 \%$ of assay maximum (Additional file 1: Figure SI3). $\mathrm{EC}_{5}$ for DHT was corresponding to a $\mathrm{BEQ}$ value of $29 \mathrm{pg} \mathrm{DHTeq} / \mathrm{L}$ in a concentrated water sample. Hence, inactive samples have a BEQ value lower than 29 pg DHTeq/L. Escher et al. [27] reported no androgenic activity in Australian drinking water sample while Jones et al. [28] report that $40 \%$ of samples of finished drinking water collected in Iowa, US, showed androgenic activity at REF 200 . We have previously reported no androgenic activity in different Swedish drinking water samples $[9,22]$. Effect-based trigger values for androgenic activities in drinking water in the range 3-11 ng DHTeq/L have been proposed [11, 15, 21]. As all samples in our study had a BEQ value below $29 \mathrm{pg}$ $\mathrm{DHTeq} / \mathrm{L}$, they are all considerably below the proposed effect-based trigger values.

Additionally, the samples were tested for antiandrogenic activity, in an assay set-up where the cells were pretreated with a fixed concentration of 200 pM DHT to activate the receptor. Neither of the ten samples showed any antiandrogenic activity, nor did they exhibit an inhibitory concentration of $20 \%$ of assay maximum (Additional file 1: Figure SI4). The $\mathrm{IC}_{20}$ value for OHF was corresponding to a $\mathrm{BEQ}$ value of $27 \mathrm{ng} \mathrm{OHFeq} / \mathrm{L}$ in a concentrated water samples. Hence, all samples in this study had a lower activity than that. We have previously detected antiandrogenic activities in samples from one Swedish drinking water treatment plant [9], in that case 
the BEQ in the sample was $2.9 \mathrm{nM}$ (i.e., $847 \mathrm{ng} \mathrm{OHFeq} / \mathrm{L}$ ). In the same study, finished drinking water from six other facilities were found to have no antiandrogenic activity, which was also the case in a previous study in the Stockholm area [22]. Beet et al. [21] recently proposed an effect-based trigger value for antiandrogenicity of $4.8 \mu \mathrm{g}$ OHFeq/L. As all samples in our study had a BEQ below $27 \mathrm{ng} \mathrm{OHFeq} / \mathrm{L}$, they are all clearly below this proposed effect-based trigger value.

\section{Aryl hydrocarbon receptor activity}

Initially, the concentrated water samples were tested for cytotoxicity in the stably transfected DR-EcoScreen cell line using MTS test at REF 50. Slight cytotoxicity was observed for five of the samples (Additional file 1: Figure SI5), but the cell viability was in no case lower than $71 \%$ at REF 50. Due to the very limited sample volumes, we were unable to produce a full dilution-series of the cell viability. However, based on the AhR activity results, we judge that this slight cytotoxicity has not interfered with the AhR activity measurement.

The samples were then tested for their AhR activating properties in a twofold four concentration dilution series starting at REF 50. We observed AhR activities, defined as at least one of the concentrations reaching over $5 \%$ of assay maximum, in eight of the ten analyzed samples (Fig. 3). For these AhR-active samples, BEQ values were calculated in the form of TCDD equivalent concentrations. BEQ and $\mathrm{EC}_{5}$ values are presented in Fig. 3. For the reference compound TCDD, the $\mathrm{EC}_{5}$ was used to calculate a corresponding $\mathrm{BEQ}$ value, taking into account that the water samples had been enriched 50 times. $\mathrm{EC}_{5}$ of TCDD was corresponding to a BEQ of $0.12 \mathrm{ng}$ $\mathrm{TCDDeq} / \mathrm{L}$ in a sample enriched 50 times. Hence, the samples not showing an activity of $5 \%$ or more at REF 50 had a $\mathrm{BEQ}$ value $<0.12 \mathrm{ng}$ TCDDeq/L.

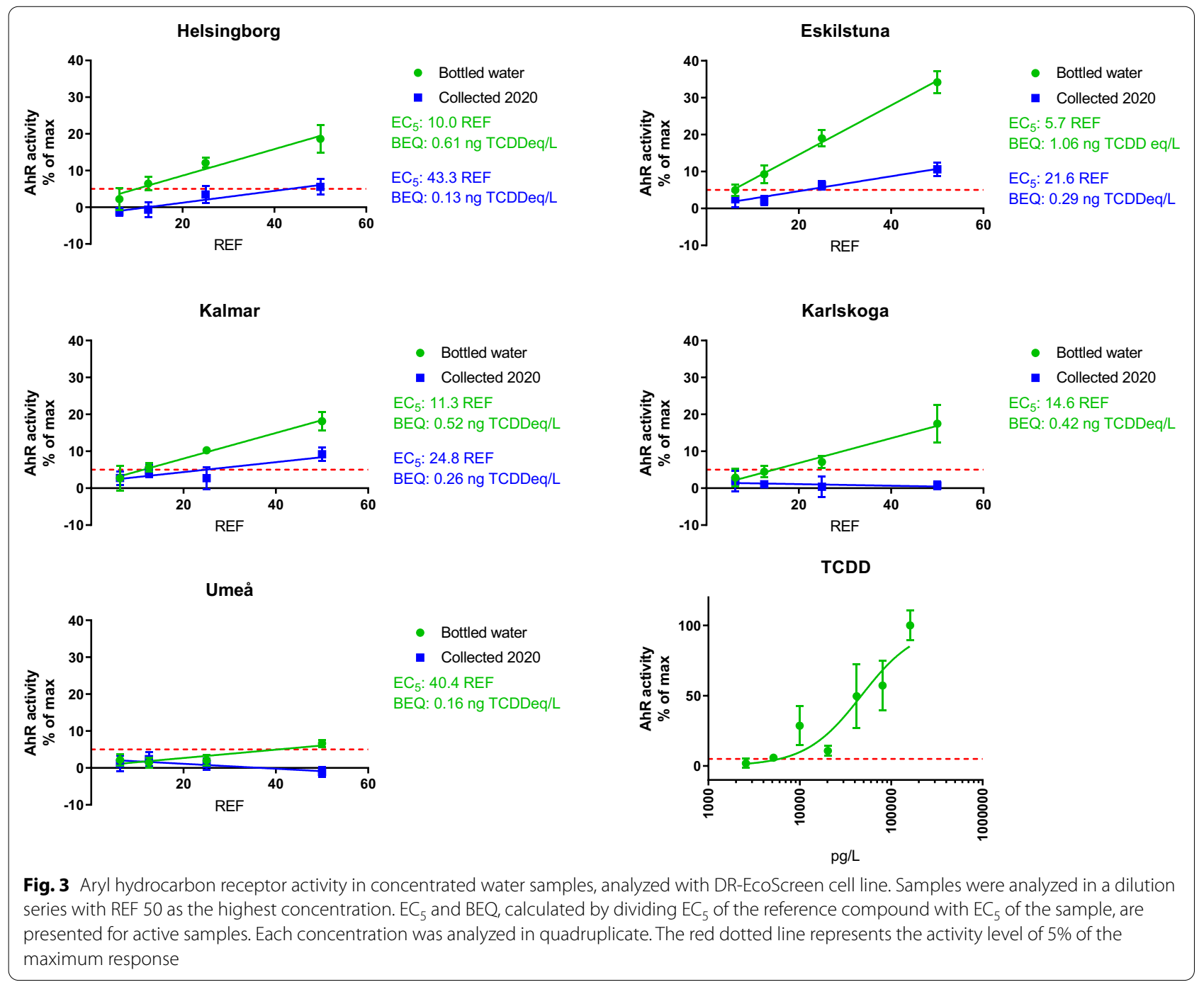


The observed AhR activities are in the range $0.1-1 \mathrm{ng} / \mathrm{L}$ TCDD equivalents. Generally, the samples collected in 2020 have a substantially lower activity than the bottled samples. In some cases (Helsingborg and Eskilstuna), the BEQ value was $70-80 \%$ lower in the samples collected in 2020 as compared to the corresponding bottled water sample. As for the estrogenic activity, where the same general trend was observed, this tendency of lower and less frequent induction of AhR activity in samples collected in 2020 versus samples collected in the 1990s could be due to improved raw water quality and/or improved treatment efficiency in the drinking water production system.

Literature data on AhR activities in drinking water is scarce. Of seven Swedish drinking water treatment plants with induced AhR activity in raw water, four had reduced activity in finished water and none had activities above $\mathrm{EC}_{10}$ at REF 50 [9]. In a screening study of 10 drinking water plants in Iowa, Jones et al. [28] found AhR activity in $67 \%$ of the finished water samples at REF 200. In an evaluation study of various bioassays, Escher et al. [27] reported an $\mathrm{EC}_{10}$ value of 8.6 REF for AhR activity in a drinking water sample from metropolitan Australia.

\section{Oxidative stress response}

Initially, the concentrated water samples were tested for cytotoxicity in the stably transfected MCF-7/AREc32 cell line using MTS test at REF 50. No cytotoxicity was observed for either of the samples (Additional file 1: Figure SI6). Thereafter, the samples were tested for oxidative stress inducing activity, but all samples were found to be negative for this activity, and neither of the samples reach an effect concentration induction ratio $1.5\left(\mathrm{EC}_{\mathrm{IR} 1.5}\right)$ at REF 50 (Additional file 1: Figure SI7). The $\mathrm{EC}_{\mathrm{IR} 1.5}$ for the reference compound was corresponding to a $\mathrm{BEQ}$ value of $5.6 \mu \mathrm{g} \mathrm{tBHQ} / \mathrm{L}$ in a concentrated water sample. Hence, all analyzed samples had a lower activity than $5.6 \mu \mathrm{g} \mathrm{tBHQ} / \mathrm{L}$ and an $\mathrm{EC}_{\mathrm{IR} 1.5}$ value higher than 50 (highest tested REF). Studies of finished drinking water from Australia and France have reported $\mathrm{EC}_{\mathrm{IR} 1.5}$ values in the range of REF 1-10 [14, 27]. We have previously reported slight oxidative stress response in other Swedish drinking water samples analyzed at REF 50 [22]. Further, we have reported $\mathrm{EC}_{\mathrm{IR} 1.5}$ values in the range of REF $21-25$ for drinking water samples collected in the Stockholm area [29] and one case of REF 26 (corresponding to a BEQ of $17 \mu \mathrm{g} \mathrm{tBHQ} / \mathrm{L}$ ) from the western parts of Sweden [9].

\section{Comparability between the samples}

It is desirable to treat all samples analyzed in a study in an identical manner, with regard to, e.g., storage time. In this particular study, it has been necessary to deviate from this principle. The bottled drinking water samples were stored in glass bottles in room temperature for approximately 25 years prior to solid phase extraction, while the samples collected in 2020 were concentrated within a week of collection. In theory, it cannot be excluded that this difference in storage time and storage conditions could contribute to the observed differences in the presence of hazardous chemicals in the bottled water samples as compared to the samples collected in 2020. However, to the best of our knowledge, there are no reports indicating that prolonged storage of water in glass bottles could contaminate the water with AhR or ER-inducing compounds. We hypothesize that the observed differences are mainly due to differences in the drinking water quality, and not the difference in storage conditions. There are, however, potential confounding factors that we have been unable to investigate experimentally, such as degradation of bioactive compounds during long-term storage, slight differences in the filling volume of the glass bottles and/or evaporation during storage, potential migration of bioactive compounds from the crown capsules used to seal the glass bottles, and the potential adsorption of bioactive compounds to the plastic bottles used for the sample collection in the year of 2020 .

\section{Future perspective on time-trend studies of hazardous chemicals in drinking water}

Long-term storage of non-concentrated water samples to evaluate time-trends in drinking water quality is far from ideal, given the potential problems discussed above. For toxicity endpoints where we already have suitable effectbased methods, comparison of BEQ values over time would be the most straightforward approach. To ensure that we have material to analyze historic samples also with newly developed effect-based methods, a potential alternative strategy could include storage of samples that had been concentrated by solid phase extraction. Highresolution mass spectrometry (HR-MS) with archiving of spectra is an interesting and promising approach to allow time-trend studies [30,31]. However, this approach alone cannot give information on the toxicity of a sample nor potential mixture effects. This highlights the need to combine advanced chemical screening with effect-based methods when analyzing drinking water quality [5].

\section{Conclusions}

In this study, we have used effect-based methods to evaluate the presence of hazardous chemicals in a unique material; approximately 25-year-old drinking water, and compared it to drinking water samples from the same drinking water treatment plants collected in 2020. In general, we observed considerably lower bioactivities in the samples collected in 2020 as compared to the samples collected in the 1990s. This is an indication that the raw water 
quality and/or treatment efficacy in these drinking water treatment facilities have improved during the quarter of a century that separate the two sampling occasions. Further, we have demonstrated the possibility to conduct an effectbased assessment of drinking water quality with as small starting volume as $330 \mathrm{~mL}$, using miniaturized bioassays, while other studies routinely use volumes in the range from 2 to $25 \mathrm{~L}$ for effect-based studies of drinking water quality $[16,22,32,33]$.

\section{Supplementary Information}

The online version contains supplementary material available at https://doi. org/10.1186/s12302-021-00476-0.

Additional file 1 : Additional text, figures and tables.

\section{Acknowledgements}

The authors are grateful to the staff at the drinking water treatment plants for practical assistance with water sampling. Geeta Mandava is acknowledged for skillful assistance with the practical laboratory work for this study.

\section{Authors' contributions}

KMP was responsible for the conceptualization of the study and the collection of the bottled drinking water samples. JL and KMP. designed the study details. JL and AO was responsible for the effect-based evaluation of the water samples and the data evaluation. All authors participated in the dissemination of the results. JL wrote the manuscript and KMP and AO critically reviewed the manuscript. All authors read and approved the final manuscript.

\section{Funding}

Open access funding provided by Swedish University of Agricultural Sciences. This study was financially supported by Magnus Bergwalls stiftelse, Svenskt Vatten Utveckling and Sweden Water Research AB.

\section{Availability of data and materials}

The datasets generated in this study are in major parts included in this publication and the supplementary data. Any additional data is available from the corresponding author on reasonable request.

\section{Declarations}

Ethics approval and consent to participate

Not applicable.

\section{Consent for publication}

Not applicable.

\section{Competing interests}

J.L. and A.O. are the founders and owners of BioCell Analytica Uppsala AB, a company providing effect-based testing services to the water sector.

\section{Author details \\ ${ }^{1}$ Department of Biomedical Sciences and Veterinary Public Health, Swedish University of Agricultural Sciences, P.O. Box 7028, 75007 Uppsala, Sweden. ${ }^{2}$ BioCell Analytica Uppsala AB, Malma Ringväg 16, SE-756 45 Uppsala, Sweden. ${ }^{3}$ Sydvatten AB, Hyllie Stationstorg 21, 21532 Malmö, Sweden. ${ }^{4}$ Sweden Water Research AB, Ideon Science Park, Scheelevägen 15, 22370 Lund, Sweden. ${ }^{5}$ Department of Building and Environmental Technology, Water Resources Engineering, Lund University, P.O. Box 118, 22100 Lund, Sweden.}

Received: 5 January 2021 Accepted: 9 March 2021

Published online: 19 March 2021

\section{References}

1. Nutrition EFSA Panel on Dietetic Products, et al. Scientific Opinion on Dietary Reference Values for water. EFSA J. 2010. 8(3): p. 1459

2. European Union.Directive (EU) 2020/2184 of the European Parliament and of the Council of 16 December 2020 on the quality of water intended for human consumption 2020. https://eur-lex.europa.eu/eli/dir/ 2020/2184/oj.

3. Escher Bl et al (2013) Most oxidative stress response in water samples comes from unknown chemicals: the need for effect-based water quality trigger values. Environ Sci Technol 47(13):7002-7011

4. König M et al (2017) Impact of untreated wastewater on a major European river evaluated with a combination of in vitro bioassays and chemical analysis. Environ Pollut 220(Part B):1220-1230

5. Escher Bl et al (2020) Tracking complex mixtures of chemicals in our changing environment. Science 367(6476):388-392

6. Brack W et al (2019) Effect-based methods are key The European Collaborative Project SOLUTIONS recommends integrating effect-based methods for diagnosis and monitoring of water quality. Environmental Sci Europe 31(1):10

7. Dingemans MML et al (2019) Risk-based approach in the revised European Union drinking water legislation: Opportunities for bioanalytical tools. Integr Environ Assess Manag 15(1):126-134

8. Dopp E et al (2019) Effect-based methods in combination with state-ofthe-art chemical analysis for assessment of water quality as integrated approach. Int J Hyg Environ Health 222(4):607-614

9. Oskarsson A et al (2021) Assessment of source and treated water quality in seven drinking water treatment plants by in vitro bioassays-Oxidative stress and antiandrogenic effects after artificial infiltration Science of The Total. Environment. 758: p. 144001

10. Escher Bl et al (2018) The advantages of linear concentration-response curves for in vitro bioassays with environmental samples. Environmental Toxicol Chem 37(9):2273-2280

11. Escher $\mathrm{Bl}$ et al (2015) Effect-based trigger values for in vitro bioassays: Reading across from existing water quality guideline values. Water Res 81:137-148

12. Cédat B et al (2016) Are UV photolysis and UV/H2O2 process efficient to treat estrogens in waters? Chemical Biological assessment at pilot scale. Water Res 100:357-366

13. WHO. Drinking water Parameter Cooperation Project. Support to the revision of Annex I Council Directive 98/83/EC on the Quality of Water Intended for Human Consumption (Drinking Water Directive) https://ec. europa.eu/environment/water/water-drink/pdf/WHO_parameter_report. pdf, 2017.

14. Neale PA et al (2019) In vitro bioassays to assess drinking water quality. Current Opinion Environ Sci Health 7:1-7

15. Brand W et al (2013) Trigger values for investigation of hormonal activity in drinking water and its sources using CALUX bioassays. Environ Int 55:109-118

16. Shi P et al (2018) Toxicological and chemical insights into representative source and drinking water in eastern China. Environ Pollut 233:35-44

17. Gou Y-Y et al (2016) Estrogenic effects in the influents and effluents of the drinking water treatment plants. Environ Sci Pollut Res 23(9):8518-8528

18. Chou HM et al (2016) An improved estrogenic activity reporter gene assay (T47D-KBluc) for detecting estrogenic activity in wastewater and drinking water. Toxicol Environmental Chemistry 98((3-4)):376-384

19. Conley JM et al (2017) Comparison of in vitro estrogenic activity and estrogen concentrations in source and treated waters from 25 U.S. drinking water treatment plants Science of The Total Environment. 579: p. 1610-1617

20. Zijl MCV et al (2017) Estrogenic activity, chemical levels and health risk assessment of municipal distribution point water from Pretoria and Cape Town South Africa. Chemosphere 186:305-313

21. Been F et al (2021) Development of a framework to derive effect-based trigger values to interpret CALUX data for drinking water quality. Water Res 193:116859

22. Rosenmai AK et al (2018) In vitro bioanalysis of drinking water from source to tap. Water Res 139:272-280

23. Maggioni S et al (2013) Screening of endocrine-disrupting phenols, herbicides, steroid estrogens, and estrogenicity in drinking water from the waterworks of 35 Italian cities and from PET-bottled mineral water. Environmental Sci Pollution Res 20(3):1649-1660 
24. Pinto B et al (2009) Screening of estrogen-like activity of mineral water stored in PET bottles. Int J Hyg Environ Health 212(2):228-232

25. Wagner $\mathrm{M}$ et al (2011) Endocrine disruptors in bottled mineral water: estrogenic activity in the E-Screen. J Steroid Biochem Mol Biol 127(1-2):128-135

26. Bach C et al (2012) Chemical compounds and toxicological assessments of drinking water stored in polyethylene terephthalate (PET) bottles: A source of controversy reviewed. Water Res 46(3):571-583

27. Escher Bl et al (2014) Benchmarking organic micropollutants in wastewater, recycled water and drinking water with in vitro bioassays. Environ Sci Technol 48(3):1940-1956

28. Jones RR et al (2020) Pilot study of global endocrine disrupting activity in lowa public drinking water utilities using cell-based assays. Sci Total Environ 714:136317

29. Lundqvist J et al (2019) Innovative drinking water treatment techniques reduce the disinfection-induced oxidative stress and genotoxic activity. Water Res 155:182-192

30. Brack W et al (2019) High-resolution mass spectrometry to complement monitoring and track emerging chemicals and pollution trends in European water resources. Environmental Sci Europe 31(1):62
31. Alygizakis NA et al (2019) NORMAN digital sample freezing platform: A European virtual platform to exchange liquid chromatography high resolution-mass spectrometry data and screen suspects in "digitally frozen" environmental samples TrAC. Trends Analytical Chemistry 115:129-137

32. Leusch FDL et al (2018) Comparison of in vitro and in vivo bioassays to measure thyroid hormone disrupting activity in water extracts. Chemosphere 191:868-875

33. Hebert A et al (2018) Bioanalytical assessment of adaptive stress responses in drinking water: A predictive tool to differentiate between micropollutants and disinfection by-products. Water Res 132:340-349

\section{Publisher's Note}

Springer Nature remains neutral with regard to jurisdictional claims in published maps and institutional affiliations.

\section{Submit your manuscript to a SpringerOpen ${ }^{\circ}$ journal and benefit from:}

- Convenient online submission

- Rigorous peer review

- Open access: articles freely available online

- High visibility within the field

- Retaining the copyright to your article

Submit your next manuscript at $\boldsymbol{\nabla}$ springeropen.com 